\title{
Rheological and Kinetic Characterization of UV Photopolymerizable Formulations as a Function of the Boehmite Nanoparticle Content
}

\author{
M. Frigione* and C. Esposito Corcione
}

Department of Engineering for Innovation, University of Salento, Lecce, Italy

\begin{abstract}
Several innovative photopolymerizable siloxane-modified acrylic formulations were characterized, both in presence or absence of organically Boehmite (OMB) nanoparticles, in order to assess their rheological and kinetic behavior. The experimental formulations were mainly intended for the surface protection of porous stones or wood elements. The importance of the experimental investigation lies in the specific requirements necessary for the proposed applications, i.e. the innovative UV coatings developed should possess adequate viscosity, photopolymerization reaction rate and time. The kinetics of the radical photopolymerization mechanism, induced by UV radiations, was studied by calorimetric analysis and FTIR spectroscopy as function of the mixtures composition and test conditions (air or nitrogen atmosphere). The addition of a silane coupling agent or a high molecular weight polysiloxane monomer to the acrylic resin was found to reduce the heat of reaction. On the other hand, the presence of Boehmite nanoparticles in the UV photopolymerizable formulations does not seem to modify the reactivity of the siloxane-modified acrylic formulations. The effect of the presence of oxygen on the kinetic reaction was also investigated and correlated to the composition of the systems. Finally, the viscosity of the formulations was studied at ambient temperature with a parallel plates rheomether as a function of composition and shear rate. The viscosity curves were also fitted according to theoretical models as function of shear rate and composition, obtaining a good agreement between experimental data and model predictions.
\end{abstract}

Keywords: Photopolymerizable acrylic resins, UV curing, photo-DSC, kinetics, rheology, bohemite nanoparticles.

\section{INTRODUCTION}

Polymers based on acrylic and methacrylic monomers are widely used for the protection and conservation of stone buildings, due to their ability to form water repellent and optically clear coatings [1-16]. There are, however, durability issues on the use of acrylic systems for the long term protection of historical buildings outdoor exposed: these systems are, therefore, preferably used for indoor applications [17-19].

In addition to the insufficient intrinsic chemical stability, the deficiency of acrylic coatings can be also be attributed to two main factors: a fairly poor adhesion to porous substrates and an insufficient water repellence to allow the drainage of the water from the surface.

In recent years, water-borne silane modified acrylic resins and partially fluorinated acrylic copolymers have been evaluated as protective coatings for porous stone surfaces [3$16]$.

In these specific applications the free radicals for the initiation of the polymerization are generally produced by the decomposition of a peroxide initiator by the heat generated with the use of IR lamps. This represents a serious limitation for the coating of large areas, particularly for outdoor applications. On the other hand, high energy radiation curing, including ultraviolet (UV) sources, have

*Address correspondence to this author at the Department of Engineering for Innovation, University of Salento, Lecce, Italy; Tel: +39-0832-297215;

Fax: +39-0832-297215; E-mail: mariaenrica.frigione@unisalento.it been widely used industrially for the curing of coatings, inks, dental restorative products and in rapid prototyping technologies [20-23]. To the best of our knowledge, little use of such systems has been made to-date as UV-curable products for the protection of stones [24, 25]. Several papers have been published from these authors [26-30] with the aim to overcome the deficiencies associated with the chemical composition of acrylic coatings as well as with the curing method to be used. In particular, suitable formulations and the use of UV and visible radiations were expressly proposed for the protection of stone based historical buildings and artworks. To achieve these objectives, a methacrylate resin system was used as the basis resin, identifying the main chemical modifications required to improve water repellence, increase adhesion to stone substrate and allow the use of UV and visible light curing methods. In a first study [29], the photopolymerization kinetics in the presence of suitable photoinitiators for the specific siloxane-modified acrylic resin system, was studied by calorimetric analysis using various light power emissions and temperatures. A trifunctional acrylic resin, selected for its high reactivity, was mixed with a silane coupling agent, containing two types of reactive functionalities - inorganic and organic - in the same molecule. As a consequence, the silane coupling agent is able to place at the interface between an inorganic substance (such as glass, metal or mineral matter) and an organic material (such as organic coating or adhesive) to bond or couple the two dissimilar materials [3, 31]. The silane coupling agent can also be an effective adhesion promoter when used as additive for coatings or adhesives. In order to be effective, the silane must migrate to the interface between 
the adhered product and the substrate. The enhancement of hydrophobicity and an appropriate modification of viscosity of the acrylic-silane mixture were achieved with the addition of a high molecular weight polysiloxane monomer, selected among the silane products. This component is reported to provide water repellency and enhance the protection, either if it is used as a post-treatment or is added to the mix [3].

The kinetic studies carried out both in nitrogen and air atmosphere on the acrylic-silane modified mixtures realized revealed that the reactivity generally decreases in air, due the inhibiting action of the oxygen towards the free radical polymerization, irrespective to the composition of the mixtures [29]. Molecular oxygen is known to strongly inhibit radical induced polymerizations because of its high reactivity toward radical species [32]. This inhibition effect is particularly pronounced for photopolymerization processes carried out on thick films because of the limited penetration of UV light. By scavenging the initiator radicals, $\mathrm{O}_{2}$ not only reduces the rate of the polymerization, thus requiring longer exposure times, but also leads to a partial loss of the optical and surface properties of air-cured coatings. As the UV-curing process of acrylate coatings is generally carried out in the presence of air, oxygen inhibition has always been a key issue [33]. Overcoming this unwanted slowing of the reaction represents a major challenge in order to use the UV photopolymerizable acrylate formulations as stone protective coatings. The effects of oxygen on the UV curing of coatings have thoroughly been investigated [30] and a proper thiol, i.e. a mercaptopropyltriethoxysilane (MPTS), was added to the siloxane modified methacrylic resin systems. It was expected to react with the dissolved $\mathrm{O}_{2}$ present in the air atmosphere, consuming it, leading, consequently, to a reduction of the production of $\mathrm{RO}_{2}^{*}$. The molecule of MPTS is able, in fact, to act as a chain transfer agent. Oxygen reacts with radicals and generates peroxide radicals which can, then, react with thiol following a hydrogen abstraction mechanism [34].

The possibility to increase the protective properties of the UV photopolymerizable acrylate formulations by the inclusion of organically modified Boehmite (OMB) nanoparticles was finally verified, measuring the hydrophobic performances of the UV nanocomposite formulations on wood elements [29]. Referring to the properties of the photopolymerized coatings applied on a glass support, the presence of the nanoparticles was found to increase the surface and scratch hardness of the coating, without any reduction in its transparency. In addition, the water absorption measurements of walnut wood coated samples confirmed that the wood elements coated with the nanocomposite absorb less water than that uncoated or coated with unfilled coatings [29]. This work is part of an ongoing research aimed at the development of new techniques and materials for the protection and consolidation of wood [35, 36].

In this paper, an experimental study was carried out with the aim of assessing the rheological and kinetic behavior of several innovative photopolymerizable siloxane-modified acrylic formulations previous developed, both in presence or absence of Boehmite nanoparticles, in order to select the best suitable formulation, in terms of reactivity and viscosity, for the specific application proposed. A preliminary study aimed to know the reactivity and the viscosity of the UV photopolymerizable coatings proposed is, in fact, necessary to identify the correct procedure to apply the coating on the substrate (i.e. spray, brushing or capillary rising) and the best conditions to reduce the time to complete the photopolymerization reactions, even in air atmosphere.

\section{MATERIALS AND METHODOLOGY}

Trimethylolpropane trimethacrylate (TMPTMA) was selected as the base methacrylic resin for its high reactivity and low viscosity $\left(45 \mathrm{mPa}^{*} \mathrm{~s}\right.$ at $\left.25^{\circ} \mathrm{C}\right)$. The product used was supplied by Cray Valley.

A trimethoxypropyl silane methacrylate monomer, produced by Dow Corning as Z6030, known as MEMO, was used as a coupling agent to enhance the adhesion of the coatings to the stone substrates.

A vinyl terminated polydimethylsiloxane (VT PDMS), supplied by Aldrich, was added to the acrylic mixture to enhance the water repellence of the coatings. The VT PDMS used has a number average molecular weight in the region of 25000.

3-Mercaptopropyltriethoxysilane (MPTS), supplied by Aldrich, was added to the siloxane modified methacrylic resin system in order to reduce the effect of inhibition of oxygen toward radical photopolymerization. MPTS has a number average molecular weight of about $238.42 \mathrm{~g} / \mathrm{mol}$.

The functionalization of VT PDMS with MPTS was performed by mixing the two components at $100^{\circ} \mathrm{C}$ in $1: 1$ molar ratio in the presence of $1 \%$ wt. of Diethylamine (DTA), purchased from Aldrich.

Organically modified Boehmite (OMB), supplied by Sasol, commercially available as Disperal-MEMO was selected as nanofiller for the methacrylic resin. The organic stabilizer for OMB nanoparticles is the trimethoxypropyl silane methacrylate (MEMO). MEMO was also used as a coupling agent to enhance the dispersion of the nanofiller into the organic coatings. It was supplied by Dow Corning as Z6030.

The photoinitiator, Irgacure 819 , supplied by Ciba, was chosen for its broad absorption characteristics within the UV region.

The chemical formula of all the products used and the UV absorption spectrum of the photoinitiator are reported in Scheme 1.

The composition of all the prepared mixtures is outlined in Table 1.

The UV-curing process of the filled and unfilled mixtures was monitored by a Differential Scanning Calorimeter (Mettler Toledo DSC1 StareSystem), able to allow the irradiation of the sample by means of a UV/visible lamp. This technique is known as photo-DSC (p-DSC). The light source, produced by a $300 \mathrm{~W}$ Xenon lamp Hamamatsu LC8, was limited to a wavelength of $370 \mathrm{~nm}$, corresponding to UV radiation. Small size samples $(0.9-1.1 \mathrm{mg})$ were used in 


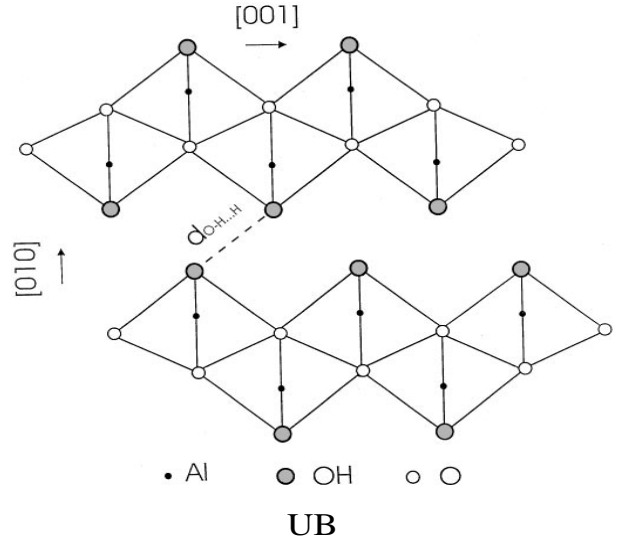

$\left[\mathrm{H}_{2} \mathrm{C}=\mathrm{C}\left(\mathrm{CH}_{3}\right) \mathrm{CO}_{2} \mathrm{CH}_{2}\right]_{3} \mathrm{CC}_{2} \mathrm{H}_{5}$

TMPTMA

\section{$\mathrm{CH}_{2}=\mathrm{C}\left(\mathrm{CH}_{3}\right)-\mathrm{COO}-\left(\mathrm{CH}_{2}\right)_{3}-\mathrm{Si}\left(\mathrm{OCH}_{3}\right)_{3}$}

MEMO

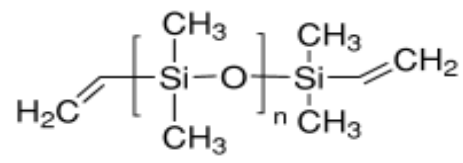

VT PDMS

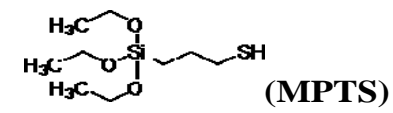

IRGACURE 819 and IRGACURE 819 DW

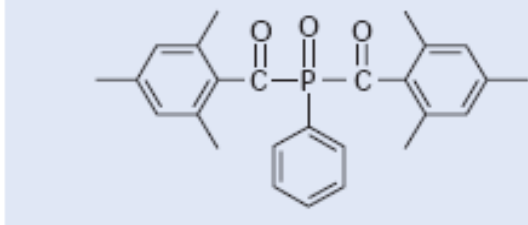

IRGACURE $819 \%$ in Acetonitrile

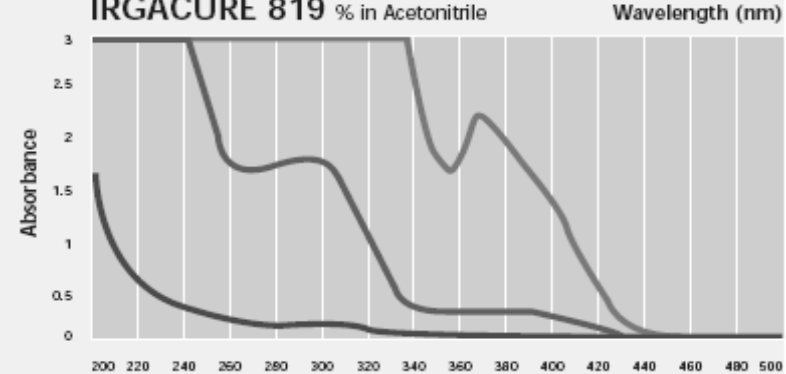

Scheme 1.

order to achieve isothermal conditions and a uniform degree of cure through the sample thickness. Isothermal scans were run at $25^{\circ} \mathrm{C}$ in nitrogen atmosphere and with radiation intensity of $9.6 \mu \mathrm{Watt} / \mathrm{mm}^{2}$. The cure of each mixture was continued until no residual exothermal signal could be detected. The photocalorimetric experiments were repeated at least three times to check the accuracy of results.

In all the DSC experiments each sample was irradiated after 30 seconds from the beginning of the test. During the first 30 seconds, in fact, the sample was maintained under dark conditions. The tangent to the heat flow curve during the test under dark conditions was used as baseline for the peak integration. This procedure reduced the possibilities that the slow recovering of the base line used for the kinetic analysis is inside of the experimental errors.

Fourier Transform Infrared Spectrometer (FT/IR-6300 Jasco) was used to monitor the consumption of the constituents in the liquid mixtures and, in turn, to analyze the cross-linking reaction mechanism. The tests were carried out in air, in order to simulate the true curing conditions. Preliminary FTIR analyses were performed on a thin layer of uncured mixtures, using a $\mathrm{NaCl}$ support. The same sample was, then, irradiated using the same Xenon lamp used in the p-DSC experiments, every $10 \mathrm{~s}$, up to $12 \mathrm{~h}$, with an irradiation intensity of $9.6 \mu \mathrm{Watt} / \mathrm{mm}^{2}$. After each crosslinking reaction step, the sample on the support was placed in the FTIR instrument, in order to determine its characteristic peaks and their intensities.

The rheological characterization of all the formulation realized was carried out in a strain controlled rheometer (Ares Rheometric Scientific). All the formulations were tested after their preparation, avoiding any aging process. The tests were performed with a plate and plate flow geometry (radius of the plate $12.5 \mathrm{~mm}$ ) in steady state mode. The experimental parameters were chosen to simulate the possible operative conditions. To this end, the tests were conducted at room temperature $\left(25^{\circ} \mathrm{C}\right)$ using a shear rate range of $0.05 \mathrm{~s}-1$ and $200 \mathrm{~s}-1$. A first sweep experiment was always followed by a second experiment performed on the same sample and using the same conditions, in order to avoid any aggregation processes. The rheological experiments were repeated at least three times to check the repeatability of results. No settling phenomena occurred in any formulation produced.

\section{RESULTS}

\section{Kinetic Characterization}

The values of the heat of reaction $\left(\mathrm{H}_{\max }\right)$ and the time to reach peak $\left(t_{\text {peak }}\right)$ measured in p-DSC for each formulation are reported in Table $\mathbf{2}$. The addition of both a silane coupling agent or a high molecular weight polysiloxane monomer to the methacrylic resin was found to reduce the heat of reaction, both in an inert or air atmosphere. This effect could be attributed to the low reactivity of the silane MEMO and VT PDMS, which was confirmed by the observation that the calculated heat of reaction of MEMO is much lower than that of the acrylic resin TMPTMA, employing the same experimental conditions, as previously reported [29]. Similar results were found by other authors for an acrylate polydimethylsiloxane (AF-PDMS) added as a reactive additive in UV-curable coating formulations based on mixtures of TMPTA (trimethylol propane triacrylate) and polyester acrylate, although in that case the 
Table 1. Weight Composition of the Prepared Mixtures

\begin{tabular}{|c|c|}
\hline Sample & Weight Composition \\
\hline $100 \mathrm{~T}_{819}$ & $100 \%$ TMPTMA + $1 \%$ Irgacure 819 \\
\hline 97T-3PDMS 819 & $97 \%$ TMPTMA + 3\% VT PDMS + 1\% Irgacure 819 \\
\hline 97T-3PDMS $\mathrm{m}_{\mathrm{m} 19}$ & 97\% TMPTMA + 3\% VT PDMS/MPTS + 1\% Irgacure 819 \\
\hline 90T-10PDMS $\mathrm{m}_{\mathrm{m} 819}$ & $90 \%$ TMPTMA + $10 \%$ VT PDMS/MPTS + 1\% Irgacure 819 \\
\hline $80 \mathrm{~T}-20 \mathrm{PDMS}_{\mathrm{m} 819}$ & $80 \%$ TMPTMA + 20\% VT PDMS/MPTS + 1\% Irgacure 819 \\
\hline $50 \mathrm{~T}-50 \mathrm{PDMS}_{\mathrm{m} 819}$ & $50 \%$ TMPTMA + 50\% VT PDMS/MPTS + 1\% Irgacure 819 \\
\hline 80T-10M-5PDMSm 819 & $80 \%$ TMPTMA + 10\% MEMO + 5\% VT PDMS/MPTS + 1\% Irgacure 819 \\
\hline 80T-10M-5PDMS+3B/M $/ \mathrm{M}_{\mathrm{m} 819}$ & $80 \%$ TMPTMA $+10 \%$ MEMO $+5 \%$ VT PDMS/MPTS $+1 \%$ Irgacure $819+3 \%$ Boehmite \\
\hline
\end{tabular}

photopolymerization was carried out only in air [37]. Moreover, the possibility of a small effect arising from the poor solubility of the UV-photoinitiator in the liquid mixture with VT PDMS cannot be excluded, as previously observed [30].

Referring to the value of the maximum heat of reaction $\left(\mathrm{H}_{\max }\right)$, the effect of MEMO is to slow down the reaction. On the other hand, a $t_{\text {peak }}$ similar to the value calculated for the TMPTMA resin is obtained when VT PDMS is also present in the mixture. The reactivity, expressed in terms of both heat developed and rate of reaction, was generally found to decrease when the UV-photopolymerization was carried out in air, always at room temperature and with a radiation intensity of $9.6 \mu \mathrm{Watt} / \mathrm{mm}^{2}$ due the inhibiting action of the oxygen towards the free radical polymerization [38]. It is well known that oxygen inhibition of free radical photopolymerization causes numerous deleterious effects on free-radically cured products, including slow polymerization rates, long induction periods, low conversion, short polymeric chain length and tacky surface properties [39-41]. The reaction mechanism of free radical photopolymerization can be represented with three subsequent steps: initiation, propagation and termination. In absence of oxygen, the initiation reactions can be schematically described by the following:

$$
\begin{aligned}
& I+h v \stackrel{k_{d}}{\longrightarrow} R^{*} \\
& R^{*}+M \stackrel{k_{i}}{\longrightarrow} M_{1}^{*}
\end{aligned}
$$

In the first step, equation (1) represents the photolysis of initiator, $I$, to give two primary radicals, $R^{*}$, while equation (2) is the chain initiation process. In this latter reaction, a primary radical reacts with monomer, $M$, to form the first repeat unit of the growing polymer chain, $M_{1}{ }^{*}$. The rate of both reactions is controlled by the kinetic constants for photolysis of the initiator, $k_{d}$, and the chain initiation, $k_{i}$, respectively.

When the curing reaction takes place in presence of oxygen, in addition to reactions schematized with equations (1) and (2), the chain initiation process comprises an additional reaction [39-41]:

$$
\mathrm{R}^{*}+\mathrm{O}_{2} \stackrel{k_{0}}{\longrightarrow} \mathrm{RO}_{2}^{*}
$$

where $k_{0}$ is the kinetic constant of the radical scavenging by $\mathrm{O}_{2}$ molecules. When the reaction is conducted in air, then, a part of radicals, $R^{*}$, are subtracted by reacting with the monomer since they can also react with oxygen molecules present in air. As a consequence, the reaction slows down and proceeds with a lower conversion.

The data reported in Table 2 confirmed that the heat of reaction of $97 \mathrm{~T}-3 \mathrm{PDMS}_{819}$ mixture is decreased by about $19 \%$ when the reaction is carried out in air instead of nitrogen. Under air atmosphere, the values of heat of reaction calculated for all the mixtures are similar, and can be primarily attributed to the reaction of the acrylic resin. Indeed, when the reaction is performed in air, it was not possible to register any heat for the reaction of MEMO or VT PDMS in presence of the UV-photoinitiator, when using a low power UV lamp, such as that operating in the p-DSC. The presence of MPTS in $97 \mathrm{~T}-3 \mathrm{PDMS}_{819}$ mixture allows to limit the decreasing of the heat of reaction, due to the oxygen effect, to only 7\%. Moreover, the presence of MPTS is able to increase the conversion of the reactive species even in presence of nitrogen. This result was explained with an increased reactivity of the VT PDMS functionalized with MPTS. In fact, while the heat of reaction of VT PDMS in isolation is about $329 \mathrm{~J} / \mathrm{g}$ [29], it increases to about $504 \mathrm{~J} / \mathrm{g}$ when VT PDMS is functionalized with MPTS. The trend observed for the time to reach the exothermic peak of all the mixtures is similar to that observed when the reaction is carried out in an inert atmosphere.

The effect of the presence of the OMB nanoparticles on the kinetic behavior of the siloxane modified methacrylate resin mixture $80 \mathrm{~T}-10 \mathrm{M}-5 \mathrm{PDMS}_{\mathrm{m} 819}$ was finally analyzed by p-DSC. The maximum heat of reaction, $\mathrm{H}_{\max }$, normalized to the weight of the organic compound (TMPTMA/MEMO/ mPDMS), and the time to reach the exothermic peak are again reported in Table 2 . The presence of Boehmite nanoparticles in the siloxane-modified acrylic resin does not affect the maximum heat of reaction, nor the time to reach the exothermic peak, that is about $12 \mathrm{~s}$. This latter result confirms that, even in presence of small amount of nanoparticles, the polymerization induced in nitrogen atmosphere by UV radiation is still very fast.

FTIR analysis was also performed on the two systems, 80T-10M-5PDMS $\mathrm{m}_{\mathrm{m} 19}, 80 \mathrm{~T}-10 \mathrm{M}-5 \mathrm{PDMS}+3 \mathrm{~B} / \mathrm{M}_{\mathrm{m} 819}$, before and after the photopolymerization process at different times, up to $12 \mathrm{~h}$, in air atmosphere, in order to deeply analyze the effect of the presence of OMB nanoparticles on the kinetic photopolymerization mechanism of the methacrylic based 
Table 2. Calorimetric Results from p-DSC

\begin{tabular}{|c|c|c|c|c|}
\hline \multirow{2}{*}{ Sample } & $\mathbf{H}_{\max }(\mathbf{J} / \mathbf{g})$ & $t_{\text {peak }}(s)$ & $\mathbf{H}_{\max }(\mathbf{J} / \mathbf{g})$ & $t_{\text {peak }}(s)$ \\
\hline & \multicolumn{2}{|c|}{ Nitrogen } & \multicolumn{2}{|c|}{ Air } \\
\hline $100 \mathrm{~T}_{819}$ & $768.5 \pm 43.1$ & $14.0 \pm 1.4$ & $321.8 \pm 32.1$ & $16.0 \pm 1.6$ \\
\hline 97 T-3 PDMS 819 & $263.2 \pm 2.6$ & $12.0 \pm 0.9$ & $212.9 \pm 1.2$ & $12.0 \pm 0.9$ \\
\hline 97 T-3 PDMS ${ }_{\mathrm{m} 819}$ & $313.7 \pm 3.0$ & $12.0 \pm 0.8$ & $298.8 \pm 1.1$ & $12.1 \pm 0.9$ \\
\hline $90 \mathrm{~T}-10 \mathrm{PDMS}_{\mathrm{m} 819}$ & $289.9 \pm 4.4$ & $13.1 \pm 2.1$ & $274.2 \pm 7.0$ & $14.9 \pm 1.2$ \\
\hline 80 T-20 PDMS ${ }_{\mathrm{m} 819}$ & $244.2 \pm 6.5$ & $17.4 \pm 3.7$ & $223.4 \pm 6.6$ & $29.4 \pm 5.1$ \\
\hline $50 \mathrm{~T}-50 \mathrm{PDMS}_{\mathrm{m} 819}$ & $232.7 \pm 5.8$ & $31.1 \pm 3.7$ & $211.0 \pm 2.8$ & $43.1 \pm 3.5$ \\
\hline 80T-10M-5PDMS ${ }_{\mathrm{m} 819}$ & $272.06 \pm 4.54$ & $12.0 \pm 1.1$ & $228.9 \pm 1.6$ & $12.9 \pm 0.2$ \\
\hline 80T-10M-5PDMS+3B/M $\mathrm{M}_{\mathrm{m} 819}$ & $274.96 \pm 5.58$ & $12.1 \pm 0.5$ & $232.4 \pm 0.9$ & $13.1 \pm 1.7$ \\
\hline
\end{tabular}

mixture. The FTIR spectra spectroscopy measurements performed on the organic and nanofilled systems before, after $6 \mathrm{~h}$ and $12 \mathrm{~h}$ of the photopolymerization reactions are reported in Figs. (1) and (2A, B), respectively.

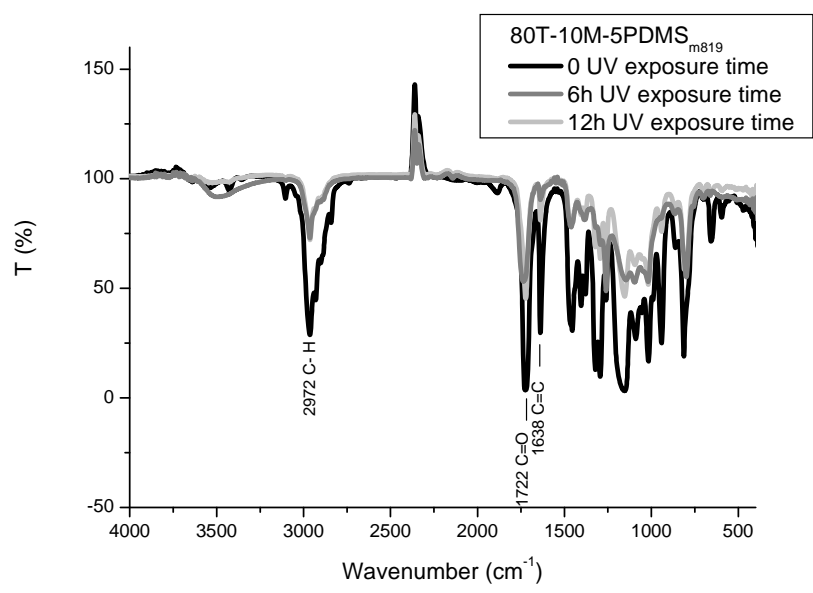

Fig. (1). FTIR curves related to $80 \mathrm{~T}-10 \mathrm{M}-5 \mathrm{PDMS}_{\mathrm{m} 819}$ system.

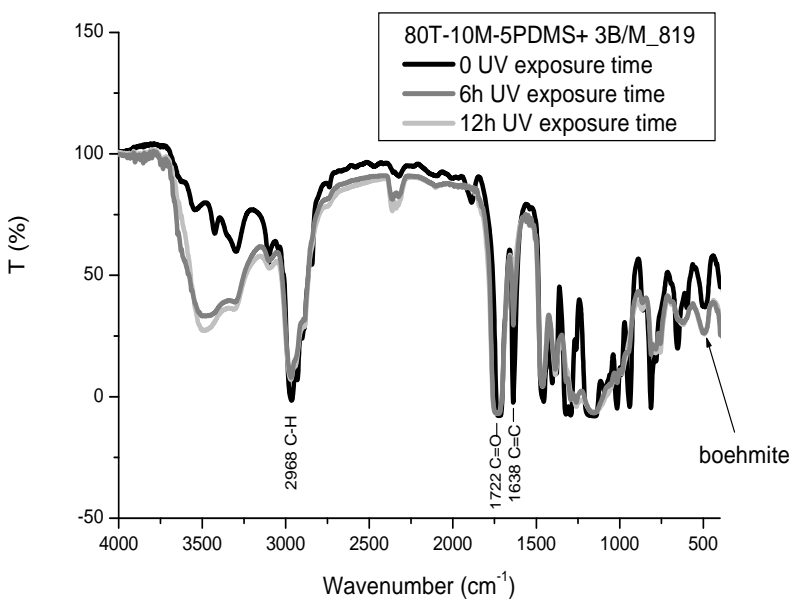

Fig. (2A). FTIR curves related to $80 \mathrm{~T}-10 \mathrm{M}-5 \mathrm{PDMS}+3 \mathrm{~B} / \mathrm{M}_{\mathrm{m} 819}$ system.

The presence of the nanofiller in the 80T-10M-5PDMS+ $3 \mathrm{~B} / \mathrm{M}_{819}$ mixture is confirmed by the peak at $500 \mathrm{~cm}^{-1}$, present only in the spectra of Fig. (2A) and corresponding to of $\mathrm{AlOOH}$ Boehmite particles, as reported in literature [42].

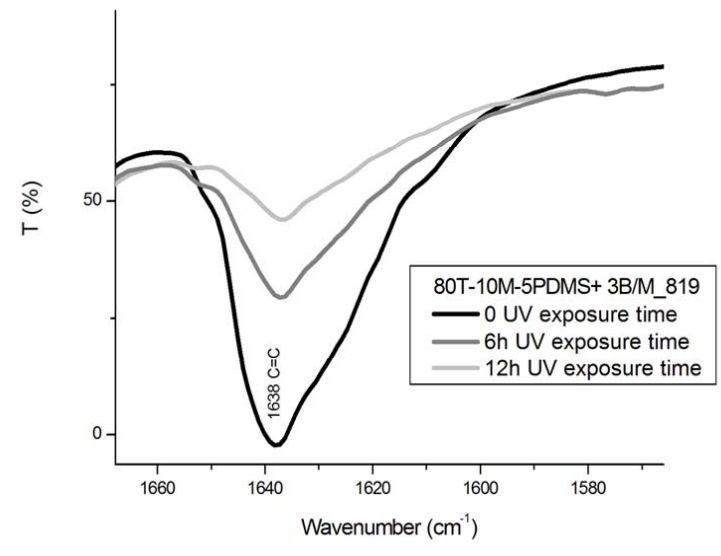

Fig. (2B). Frame of the peak at $1638 \mathrm{~cm}^{-1}$, related to the double $\mathrm{C}=\mathrm{C}$ bond of the organic monomer, from FTIR data of the system 80T-10M-5PDMS+3B/M $\mathrm{M}_{\mathrm{m} 819}$.

The presence of the peak at $1638 \mathrm{~cm}^{-1}$, related to the double $\mathrm{C}=\mathrm{C}$ bond of the organic monomer, can be still noticed in all the spectra reported in Figs. $(\mathbf{1}, \mathbf{2 A})$ and better evidenced in the frame of Fig. (2B). This result suggests that the UV-curing of the organic unfilled and nanofilled mixtures was not complete in air, even after $12 \mathrm{~h}$ of exposure to the UV radiation. This means that the inhibition effect of oxygen towards free radical photopolymerization, even if reduced by the presence of MPTS [30], was not completely eliminated. The identification of the main peaks with the associated chemical bonds and wavenumbers is reported in Table 3 .

The maximum extent of reaction $(\alpha)$ for both systems was, then, determined as follows [43]:

$$
\alpha=\frac{\left(A_{C=C}\right)_{t i}-\left(A_{C=C}\right)_{t 0}}{\left(A_{C=C}\right)_{t 0}}
$$

where $\left(\mathrm{A}_{\mathrm{C}=\mathrm{C}}\right)_{\mathrm{ti}}$ is the absorbance related to $\mathrm{C}=\mathrm{C}$ bond at the time $t_{i},\left(A_{C=C}\right)_{t 0}$ is the absorbance of the invariant related to $\mathrm{C}=\mathrm{C}$ bond the initial time $\mathrm{t}_{0}$. 
Table 3. Identification of the Main FTIR Peaks with the Associated Chemical Bonds and Wave Numbers

\begin{tabular}{|c|c|c|}
\hline \multirow{2}{*}{$\begin{array}{c}\text { Chemical } \\
\text { Bond }\end{array}$} & \multicolumn{2}{|c|}{ Wave Numbers $\left(\mathrm{cm}^{-1}\right)$} \\
\hline & 80T-10M-5PDMS ${ }_{\mathrm{m} 819}$ & 80T-10M-5PDMS+3B/M $\mathrm{M}_{\mathrm{m} 819}$ \\
\hline $\mathrm{CH}_{\text {stretching }}$ & 2972 & 2966 \\
\hline $\mathrm{CH}_{\text {bending }}$ & 1470 & 1470 \\
\hline $\mathrm{C}=\mathrm{O}_{\text {stretching }}$ & 1722 & 1722 \\
\hline $\mathrm{C}=\mathrm{C}_{\text {stretching }}$ & 1638 & 1638 \\
\hline $\mathrm{C}-\mathrm{O}_{\text {stretching }}$ & 1160 & 1160 \\
\hline $\mathrm{P}=\mathrm{O}_{\text {stretching }}$ & 1297 & 1297 \\
\hline Si-O-C stretching & 1017 & 1017 \\
\hline $\mathrm{Si}-\mathrm{H}_{3}$ bending asimm. & 935 & 935 \\
\hline $\mathrm{AlOOH}$ & ---- & 500 \\
\hline
\end{tabular}

The results obtained are reported in Fig. (3).

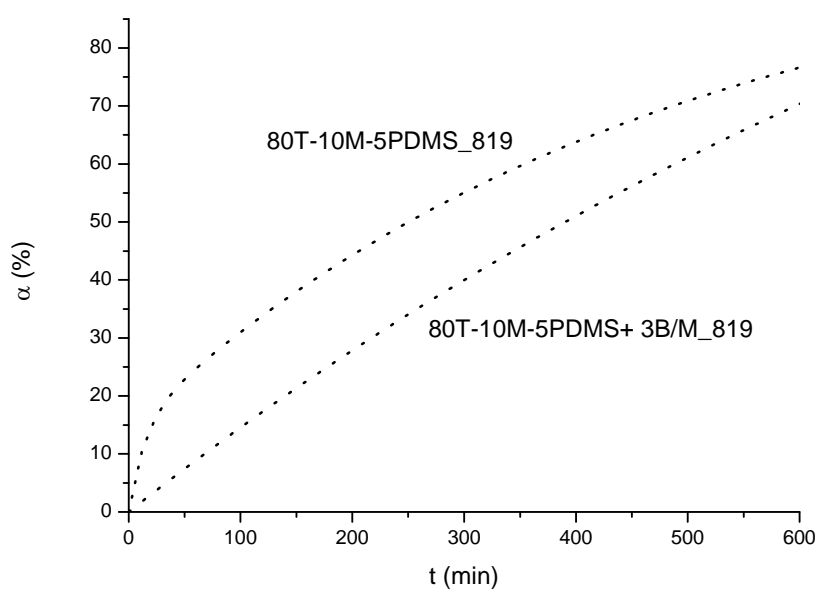

Fig. (3). Maximum extent of reaction $(\alpha)$ for $80 \mathrm{~T}-10 \mathrm{M}-5 \mathrm{PDMS}_{\mathrm{m} 819}$ and $80 \mathrm{~T}-10 \mathrm{M}-5 \mathrm{PDMS}+3 \mathrm{~B} / \mathrm{M}_{\mathrm{m} 819}$ systems, obtained from FTIR curves.

It can be noticed that, after a 600-minute exposure to UV radiation in air atmosphere, both the systems achieve a final $\alpha$ value not higher than $70 \%$. Moreover, the nanofilled system shows a slightly lower extent of reaction, even though the difference in reactivity is reduced for longer exposure times.

As final consideration, the UV curing times required to the experimental systems, in the order of 10 hours, are still much lower than the typical curing times required to the systems thermally cured at room temperature, that are in the order of weeks [44].

\section{Rheological Characterization}

In Fig. (4), the viscosity of both neat methacrylic resin photo-initiated with Irgacure $819\left(100 \mathrm{~T}_{819}\right)$ and the same photo-initiated resin in presence of $3 \%$ wt. of VT PDMS $\left(97 \mathrm{~T}-3 \mathrm{PDMS}_{819}\right)$, is reported as a function of the shear rate. Both mixtures display a Newtonian behavior and no differences in the rheological behavior were observed from two consecutive steps performed on the same specimen. The presence of $3 \% \mathrm{wt}$. of VT PDMS in the photo-initiated TMPTMA resin allows to slightly increase the viscosity of the mixture, i.e. from $38 \mathrm{mPa}^{*} \mathrm{~s}$ to $46 \mathrm{mPa}^{*} \mathrm{~s}$.

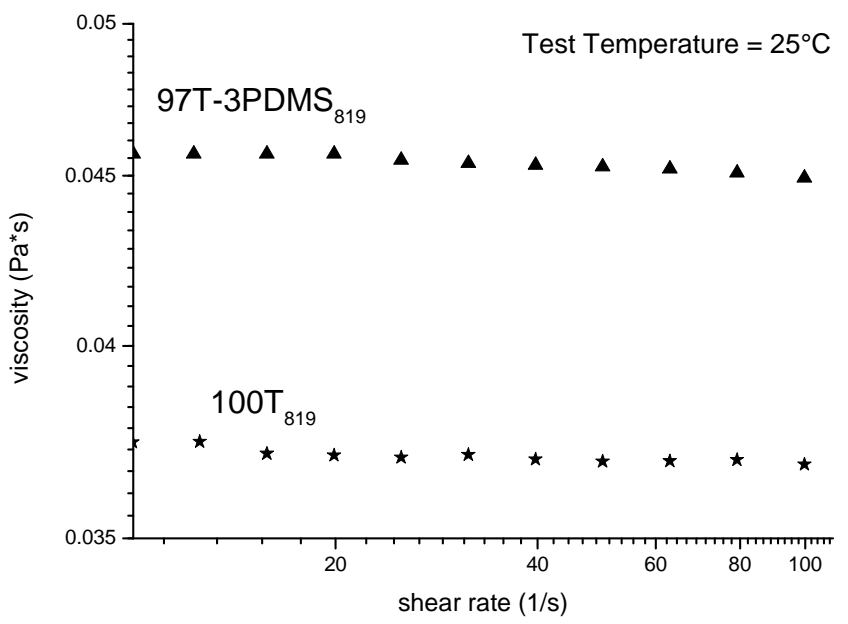

Fig. (4). Experimental viscosity curves for some of the mixtures realized as function shear rate.

In order to further increase the viscosity of the protective mixtures to a more appropriate value, as required for the specific application, the VT PDMS content in the mixtures with TMPTMA was increased from $3 \%$ wt. to $50 \%$ wt. Moreover, since radical photopolymerization reaction is slowed by the presence of oxygen in the atmosphere, VT PDMS was previously functionalized with MPTS monomer (as previously described in the kinetic characterization section), in order to reduce this negative effect. The rheological curves of the mixtures containing VT PDMS/MPTS are reported in Fig. (5).

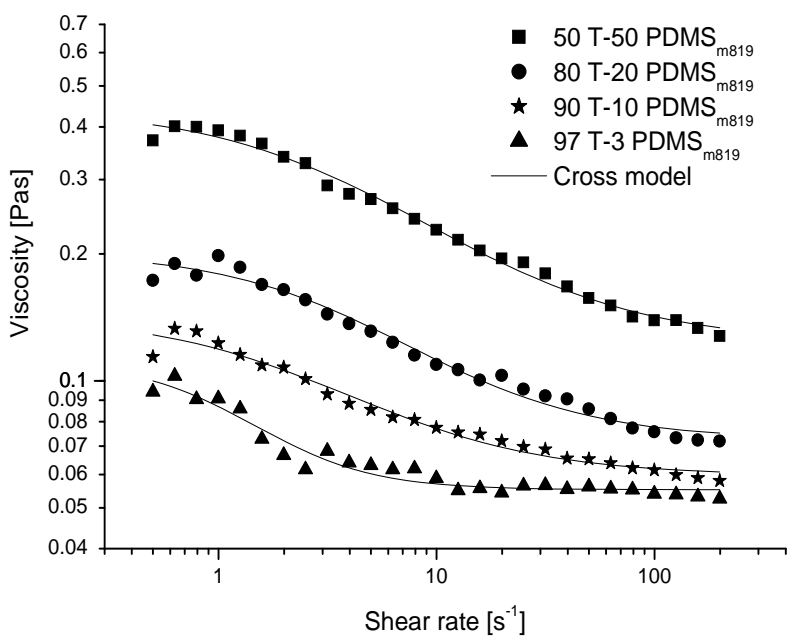

Fig. (5). Experimental viscosity curves for some of the mixtures realized as function shear rate with the predictions of Cross model (full lines).

All the mixtures reported in Fig. (5) exhibit a pseudoplastic rheological behavior, showing a viscosity decreasing with shear rate. The presence of MPTS determines a change in the rheological behavior from Newtonian (Fig. 4) to pseudo-plastic (Fig. 5) in the mixture composed by $97 \%$ 
Table 4. Model Parameters for Cross Model Fitting Experimental Viscosity Data

\begin{tabular}{|c|c|c|c|c|}
\hline Mixtures & $\eta_{\mathbf{0}}\left(\mathbf{P a}{ }^{*} \mathbf{s}\right)$ & $\eta_{\infty}(\mathbf{P a} * \mathbf{s})$ & $\lambda(\mathbf{s})$ & $\mathbf{m}$ \\
\hline \hline $97 \mathrm{~T}-3 \mathrm{PDMS}_{\mathrm{m} 819}$ & $0.44 \pm 0.002$ & $0.12 \pm 0.0097$ & $0.22 \pm 0.01$ & $0.88 \pm 0.12$ \\
\hline $90 \mathrm{~T}-10 \mathrm{PDMS}_{\mathrm{m} 819}$ & $0.20 \pm 0.010$ & $0.07 \pm 0.0046$ & $0.22 \pm 0.04$ & $0.96 \pm 0.13$ \\
\hline $80 \mathrm{~T}^{2} 20 \mathrm{PDMS}_{\mathrm{m} 819}$ & $0.14 \pm 0.012$ & $0.06 \pm 0.0028$ & $0.39 \pm 0.13$ & $1.01 \pm 0.18$ \\
\hline $50 \mathrm{~T}-50 \mathrm{PDMS}_{\mathrm{m} 819}$ & $0.11 \pm 0.012$ & $0.06 \pm 0.0010$ & $0.85 \pm 0.26$ & $1.60 \pm 0.38$ \\
\hline
\end{tabular}

TMPTMA $+3 \%$ VT PDMS $+1.5 \%$ Irgacure 819 . This feature could be attributed to the reaction of functionalization between VT PDMS and MPTS monomers. It is also clear that the viscosity of the liquid mixtures increases by increasing the content of VT PDMS functionalized with MPTS. The viscosity achieves an adequate value for the application as protective coatings for porous stones elements in presence of $50 \%$ wt. of VT PDMS/MPTS (i.e. about 0.3-0.5 Pa*s). Moreover, the occurrence of a pseudo-plastic behavior at the lowest shear rate values would exclude any particle settling during the preparation stage; a lower value of viscosity at medium shear rate values would be an advantage during the application stage, in particular by spreading.

The viscosity curves obtained were fitted according to the Cross model [30, 45]:

$$
\eta=\eta_{\infty}+\frac{\eta_{0}-\eta_{\infty}}{1+(\lambda \dot{\gamma})^{m}}
$$

where $\eta_{0}$ and $\eta_{\infty}$ are the lower and upper Newtonian limit viscosities, $\lambda$ is the reciprocal of the shear rate at which the calculated value of $\eta$ equals $\eta_{0}$, and the parameter $m$ is related to the power law index, $n$, by the expression: $m=1-n$. The fitted curves are also reported in Fig. (5), and fitting parameters are reported in Table 4, showing a good agreement between the experimental results and model predictions.

In order to quantify the effect of the presence of $\mathrm{OMB}$ nanofiller in $80 \mathrm{~T}-10 \mathrm{M}-5 \mathrm{PDMS} \mathrm{M}_{\mathrm{m} 19}$ formulation and, in turn, to have an indirect measure of the dimensions of the nanoparticles dispersed in same suspension, steady rheological measurements were also performed on $80 \mathrm{~T}$ $10 \mathrm{M}-5 \mathrm{PDMS} \mathrm{m}_{\mathrm{m} 19}$ and $80 \mathrm{~T}-10 \mathrm{M}-5 \mathrm{PDMS}+3 \mathrm{~B} / \mathrm{M}_{\mathrm{m} 819}$ suspensions. The results, reported in Fig. (6), show that both mixtures posses a pseudo-plastic behavior and that the viscosity of the unfilled suspensions increases in presence of $3 \%$ wt. of OMB. This increase is particular evident for shear rates lower than $10 \mathrm{~s}^{-1}$.

Since the rheology of multi-phase systems, and more specifically of solid-liquid suspensions, was the object of numerous investigations, both theoretical and experimental starting from the work of Einstein [46], it was found that the viscosity of a suspension depends on the dimensions of the solid particles, i.e. by increasing of the dimension of the particles an increase of the viscosity of the suspension is obtained. The Einstein equation can be applied to very dilute suspensions (solid volume fraction $\Phi<0.02$ ) of rigid spheres in a Newtonian field, i.e.:

$\eta_{r}=1+k_{1} * \Phi$

where: $\eta_{\mathrm{r}}$ is the relative viscosity of the suspension, calculated as the ratio between the viscosity of the filled suspensions, $\eta$, and the viscosity of the suspending medium, $\eta_{\mathrm{s}}$. The parameter $\mathrm{k}_{1}$ takes into account the shape of the particles in suspension and equals 2.5 for spherical particles, as in Einstein equation.

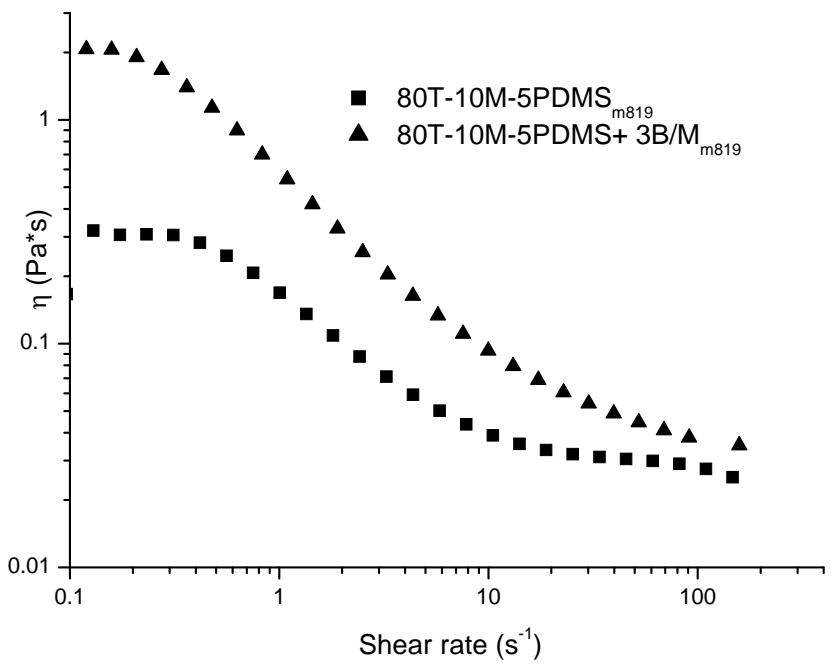

Fig. (6). Rheological curves of $80 \mathrm{~T}-10 \mathrm{M}-5 \mathrm{PDMS}_{\mathrm{m} 819}$ and $80 \mathrm{~T}$ $10 \mathrm{M}-5 \mathrm{PDMS}+3 \mathrm{~B} / \mathrm{M}_{\mathrm{m} 819}$ mixtures.

\section{CONCLUSIONS}

Several novel photopolymerizable siloxane-modified acrylic formulations, both in presence or without organically Boehmite (OMB) nanoparticles, were prepared and characterized, in order to select the more suitable composition to be proposed as protective coating for porous stones. To this aim, a deep analysis of the time, the rate of photopolymerization reaction and the viscosity of the experimental UV formulations was performed.

The kinetic results, obtained from p-DSC measurements, evidenced that, in nitrogen atmosphere, the photopolymerization of all the formulations produced is very fast, even in presence of small amount of nanoparticles. On the other hand, in air atmosphere, the effect of oxygen inhibition toward free radical photopolymerization reaction can be reduced by introducing a proper thiol (MPTS). However, FTIR analysis showed that the systems achieve a final $\alpha$ value below $70 \%$. Moreover, the nanofilled system displays a slightly lower extent of reaction, even though the 
difference in reactivity is reduced for longer exposure times. It must be underlined that the UV curing times required to the experimental systems developed, in the order of 10 hours, are still much lower than the typical curing times required for their thermally-induced curing at room temperature, in the order of weeks.

Referring to the viscosity of the photo-curable methacrylic-siloxane based formulations, a pseudo-plastic behavior was generally found, well fitted by the Cross relationship. The mixtures analyzed possess a viscosity suitable for the proposed application in all range of shear rate investigated, even in presence of a small amount of Boehmite nanoparticles.

\section{CONFLICT OF INTEREST}

The authors declare that they have no competing interests.

\section{ACKNOWLEDGEMENTS}

Declared none.

\section{REFERENCES}

[1] Lazzarini M, Laurenzi TM. Il Restauro della Pietra. Padova, Italy: CEDAM: 1986.

[2] Torrisi A. Evaluation of five fluorinated compounds as calcarenite protectives. J Cult Herit 2008; 9: 135-45.

[3] Horie CV. Materials for Conservation. Oxford, UK: ButterworthHeinemann 1987.

[4] Toniolo L, Poli T, Castelvetro V, Manariti A, Chiantore O, Lazzari M. Tailoring new fluorinated acrylic copolymers as protective coatings for marble. J Cult Herit 2002; 3: 309-16.

[5] Amoroso G. Trattato della scienza e conservazione dei monumenti. Firenze, Italy: Alinea Editrice 2002.

[6] Miliani C, Ombelli M, Morresi A, Romani A. Spectroscopic study of acrylic resins in solid matrices. Surf Coating Technol 2002; 152: 276-80.

[7] Hansen E, Lowinger R, Sadoff F. Consolidation of porous paint in a vapor-saturated atmosphere: a technique for minimizing changes in the appearance of powdering, matte paint. J Am Inst Conserv 1993; 32: 1-14.

[8] Cardiano P, Sergi S, Lazzari M, Piraino P. Epoxy-silica polymers as restoration materials. Polymer 2002; 43: 6635-40.

[9] Alessandrini G, Aglietto M, Castelvetro V, Ciardelli F, Peruz R, Toniolo L. Comparative evaluation of fluorinated and unfluorinated acrylic copolymers as water-repellent coating materials for stone. J Appl Polym Sci 2000; 76: 962-77.

[10] Chiantore O, Lazzari M. Photo-oxidative stability of paraloid acrylic protective polymers. Polymer 2001; 42: 17-27.

[11] Hansen CM. Water transport and condensation in fluoropolymer films. Progr Org Coating 2001; 42: 167-78.

[12] Della VC, Penati A, Peruzzi R, Siboni S, Toniolo L, Colombo C. The combined effect of roughness and heterogeneity on contact angles: the case of polymer coating for stone protection. J Adhesion Sci Technol 2000; 14: 277-303.

[13] Torrisi A. XPS study of five fluorinated compounds deposited on calcarenite stone. Appl Surf Sci 2008; 254: 2650-8.

[14] Aglietto M, Castelvetro V, Ciardelli F, Fassina V, Botteghi C, Matteoli U. Designing fluorinated polymers as durable, highly efficient coating materials for stone protection. 5th International Symposium on the Conservation of Monuments in the Mediterranean Basin. Seville Spain 2000.

[15] Kotlik P, Ignas J, Zelinger J. Some ways of polymerizing methyl methacrylate in sandstone. Stud Conserv 1980; 25: 1-13.

[16] Priest C, Stevens N, Sedev R, Skinner W, Ralston J. Inferring wettability of heterogeneous surfaces by ToF-SIMS. J Colloid Interface Sci 2008; 320: 563-8.

[17] Lettieri M, Calia A, Mecchi AM, Quarta G. Consolidation treatments on highly porous calcareous stone: a review of methodologies and products. Proceedings of 6th International Sympsium on the Conservation of Monuments in the Mediterranean Basin. Lisbon Portugal 2004.
[18] Kulinich SA, Farzaneh M. Hydrophobic properties of surfaces coated with fluoroalkylsiloxane and alkylsiloxane monolayers. Surf Sci 2004; 573: 379-90.

[19] Fort Gonzalez R, Lopéz de Azcona MC, Mingarro MF, Alvarez de $\mathrm{BM}$, Rodriguez BJ. A comparative study of the efficiency of siloxanes, methacrylates and microwax-based treatments applied to the stone materials of the Royal Palace of Madrid, Spain. Proceedings of 9th International Congress on Deterioration and Conservation of Stone; Eds. V. Fassina. Amsterdam, The Netherlands: Elsevier 2000.

[20] Greco A, Licciulli A, Maffezzoli A. Stereolitography of ceramic suspensions. J Mater Sci 2001; 36: 99-105.

[21] Esposito CC, Greco A, Montagna F, Licciulli A, Maffezzoli A. Silica moulds built by stereolithography. J Mater Sci 2005; 40 4899-904.

[22] Licciulli A, Esposito CC, Greco A, Amicarelli V, Maffezzoli A. Laser stereolitography of $\mathrm{ZrO}_{2}$ toughened $\mathrm{Al}_{2} \mathrm{O}_{3}$. J Eur Cer Soc 2005; 1581-9.

[23] Grassia L, D'Amore A. Finite element calculation of residual stress in dental restorative material. AIP Conf Proc 2012; 1459: 312-5.

[24] Nelson EW, Carter TP, Scranton AB. Fluorescence monitoring of cationic photopolymerizations: divinyl ether polymerizations photosensitized by anthracene derivatives. Macromol 1994; 27: 1013-9.

[25] Decker C. Photoinitiated crosslinking polymerisation. Progr Polym Sci 1996; 21: 593-650.

[26] Esposito CC, Previderio A, Frigione M. Kinetics characterization of a novel photopolymerizable siloxane-modified acrylic resin. Therm Acta 2010; 509: 56-61.

[27] Esposito CC, Frigione M. Influence of stone particles on the rheological behavior of a novel photopolymerizable siloxanemodified acrylic resin. J Appl Polym Sci 2011; 122: 942-7.

[28] Esposito CC, Frigione M. UV-cured siloxane-modified acrylic coatings containing birifrangent calcarenitic stone particles: photocalorimetric analysis and surface properties. Progr Org Coating 2011; 72: 522-7.

[29] Esposito CC, Frigione M. UV-cured polymer-boehmite nanocomposite as protective coating for wood elements. Progr Org Coating 2012; 74: 781- 7 .

[30] Esposito CC, Frigione M. Factors influencing photo-curing kinetics of novel UV-cured siloxane-modified acrylic coatings: oxygen inhibition and composition. Therm Acta 2012; 534: 21-7.

[31] Di Lorenzo ML, Frigione M. Compatibilization criteria and procedures for binary blends: a review. J Polym Eng 1997; 17: 42959.

[32] Fouassier JP. Photoinitiation, photopolymerization and photocuring. New York: Hanser Publishers 1995.

[33] Decker C, Jenkins AD. Kinetic approach of oxygen inhibition in ultraviolet- and laser-induced polymerizations. Macromol 1985; 18: 1241-4.

[34] Hoyle CE, Keel M, Kim KJ. Photopolymerization of 1,6hexanediol diacrylate with deoxybenzoin as photoinitiator. Polymer 1988; 29: 2033-40

[35] Lionetto F, Frigione M. Mechanical and natural durability properties of wood treated with a novel organic preservative/consolidant product. Mater Design 2009; 30: 3303-7.

[36] Lionetto F, Frigione M. Effect of novel consolidants on mechanical and absorption properties of deteriorated wood by insect attack. J Cult Herit 2012; 13: 195-203.

[37] Kim HK, Ju HT, Hong JW. Characterization of UV-cured polyester acrylate films containing acrylate functional polydimethylsiloxane. Eur Polym J 2003; 39: 2235-41.

[38] Tryson GR, Schultz AR. A calorimetric study of acrylate photopolymerization. J Polym Sci B Polym Phys 1979; 17: 205975.

[39] Lee TY, Guymon CA, Sonny JE, Hoyle CE. The effect of monomer structure on oxygen inhibition of (meth)acrylates photopolymerization. Polymer 2004; 45: 6155-62.

[40] Goodnera MD, Bowman CN. Development of a comprehensive free radical photopolymerization model incorporating heat and mass transfer effects in thick films. Chem Eng Sci 2002; 57: 887900.

[41] Studer K, Decker C, Beck E, Schwalm R. Overcoming oxygen inhibition in UV-curing of acrylate coatings by carbon dioxide inerting, Part I. Progr Org Coating 2003; 48: 92-100. 
[42] Chen Q, Udomsangpetch C, Shen SC, Liu YC, Chen Z, Zeng XT. The effect of $\mathrm{AlOOH}$ boehmite nanorods on mechanical property of hybrid composite coatings. Thin Solid Films 2009; 517: 4871-4.

[43] Kerbouch P, Lebaudy P, Lecamp L, Bunel C. Numerical simulation to correlate photo-polymerization kinetics monitoring by RTNIRspectroscopy and photocalorimetry. Therm Acta 2004; 410: 73-8.

[44] Lettieri M, Lionetto F, Frigione M, Prezzi L, Mascia L. Cold-cured epoxy-silica hybrids: Effects of large variation in specimen thickness on the evolution of the Tg and related properties. Polym Eng Sci 2011; 51:358-68

[45] Esposito CC, Frigione M. A novel procedure able to predict the rheological behavior of trifunctional epoxy resin/hyperbranched aliphatic polyester mixtures. Polym Test 2009; 28: 830-5.

[46] Dealy JM, Wissbrun KF, Reinhold V. Melt Rheology and its role in plastics processing theory and applications. New York: Van Nostrand Reinhold 1990.

(C) Frigione and Corcione; Licensee Bentham Open.

This is an open access article licensed under the terms of the Creative Commons Attribution Non-Commercial License (http://creativecommons.org/licenses/by-nc/3.0/) which permits unrestricted, non-commercial use, distribution and reproduction in any medium, provided the work is properly cited. 